
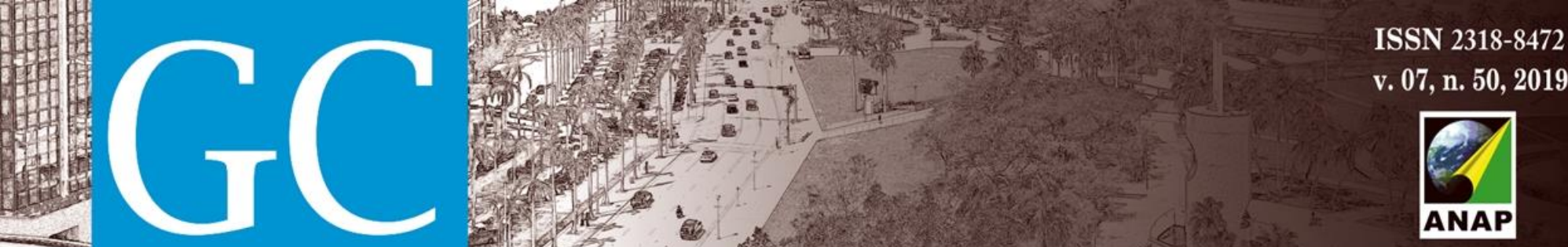

Revista Nacional de Gerenciamento de Cidades

\title{
Espaços livres como ativadores comunitários
}

Opened spaces as community activators

Espacios libres como activadores comunitarios

Isabela Sollero Lemos

Doutoranda em Arquitetura e Urbanismo pela Universidade de São Paulo isabela.sollero@usp.br

\section{Janaina Marx}

Doutoranda em Arquitetura e Urbanismo pela Universidade de São Paulo;

Professora na Universidad Central del Ecuador jmarx@usp.br 


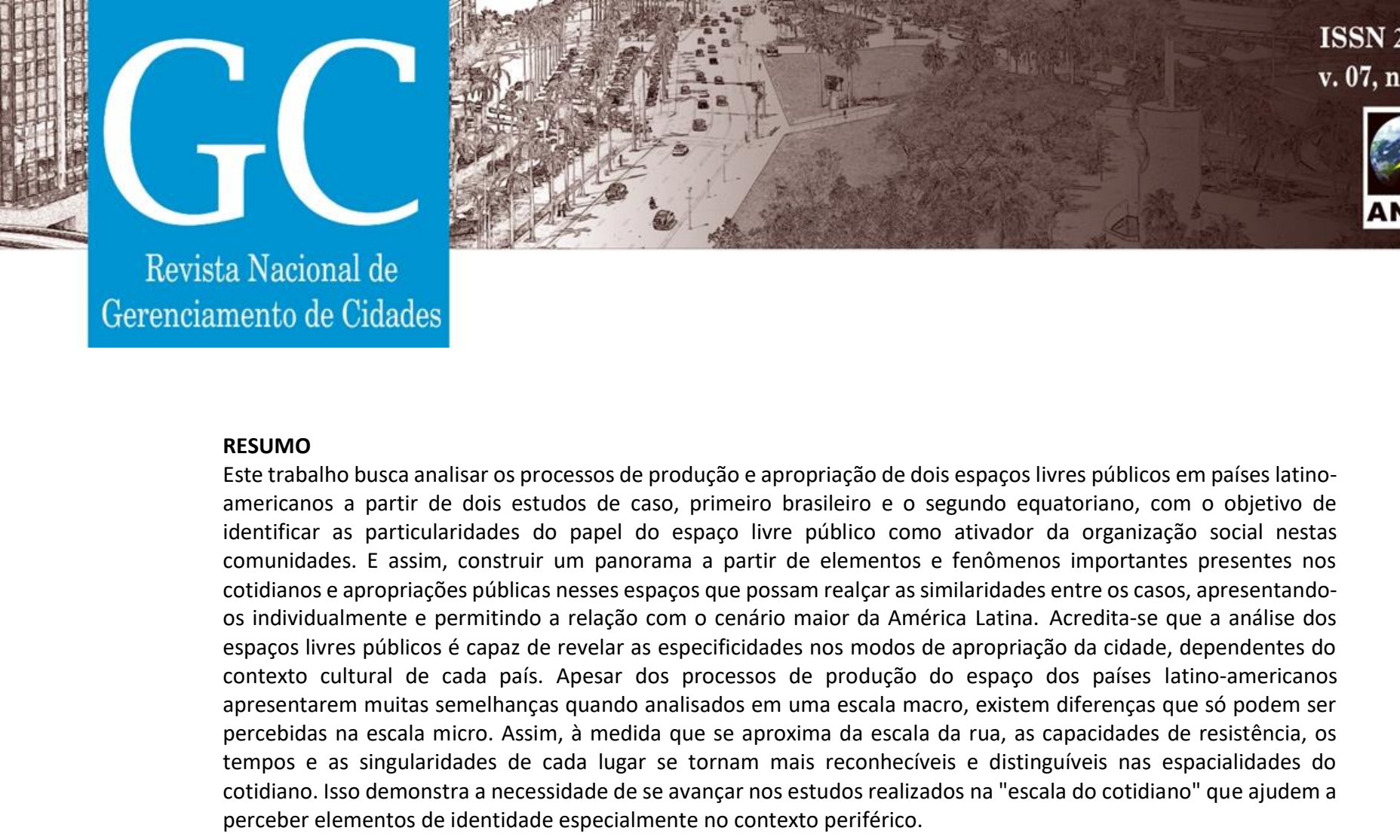

PALAVRAS-CHAVE: Espaços livres públicos. América Latina. Cotidiano.

\begin{abstract}
This paper analyzes the processes of production and appropriation of two public opened spaces in Latin American countries from two case studies, the first Brazilian and the second Ecuadorian, aiming to identify the particularities of the role of public free space as activator of social organization in these communities. Therefore, to construct a panorama from elements and important phenomena present in daily life and public appropriations in these spaces that can highlight the similarities between the cases, presenting them individually and allowing the relationship with the larger scenario in Latin America. It is believed that the analysis of public opened spaces is able to reveal the specificities in the ways of appropriation of the city, depending on the cultural context of each country. Although the processes of space production in Latin American countries have many similarities when analyzed on a macro scale, there are differences that can only be perceived on the micro scale. Thus, as one approaches the scale of the street, the resistance capacities, times, and singularities of each place become more recognizable and distinguishable in everyday spatialities. This demonstrates the need to advance studies on the "everyday scale" that help to understand identity elements especially in the peripheral context.
\end{abstract}

KEY WORDS: Free opened spaces. Latin America. Everyday.

\title{
RESUMEN
}

Este artículo analiza los procesos de producción y apropiación de dos espacios libres públicos en países latinoamericanos a partir de dos estudios de caso, el primero brasileño y el segundo ecuatoriano, con el objetivo de identificar las particularidades del papel del espacio libre público como activador de organización social en estas comunidades. Por lo tanto, construir un panorama a partir de elementos y fenómenos importantes presentes en la vida cotidiana y las apropiaciones públicas en estos espacios que puedan resaltar las similitudes entre los casos, presentándolos individualmente y permitiendo la relación con el escenario más amplio en América Latina. Se cree que el análisis de los espacios libres públicos puede revelar las especificidades en las formas de apropiación de la ciudad, dependiendo del contexto cultural de cada país. Aunque los procesos de producción de espacio en los países latinoamericanos tienen muchas similitudes cuando se analizan en la escala macro, existen diferencias que solo se pueden percibir en la escala micro. Así, a medida que uno se acerca a la escala de la calle, las capacidades de resistencia, los tiempos y las singularidades de cada lugar se vuelven más reconocibles y distinguibles en las espacialidades cotidianas. Esto demuestra la necesidad de avanzar en los estúdios sobre la "escala del cotidiano" que ayudan a comprender los elementos de identidad, especialmente en el contexto periférico.

PALABRAS CLAVE: Espacios libres públicos America Latina. Cotidiano. 


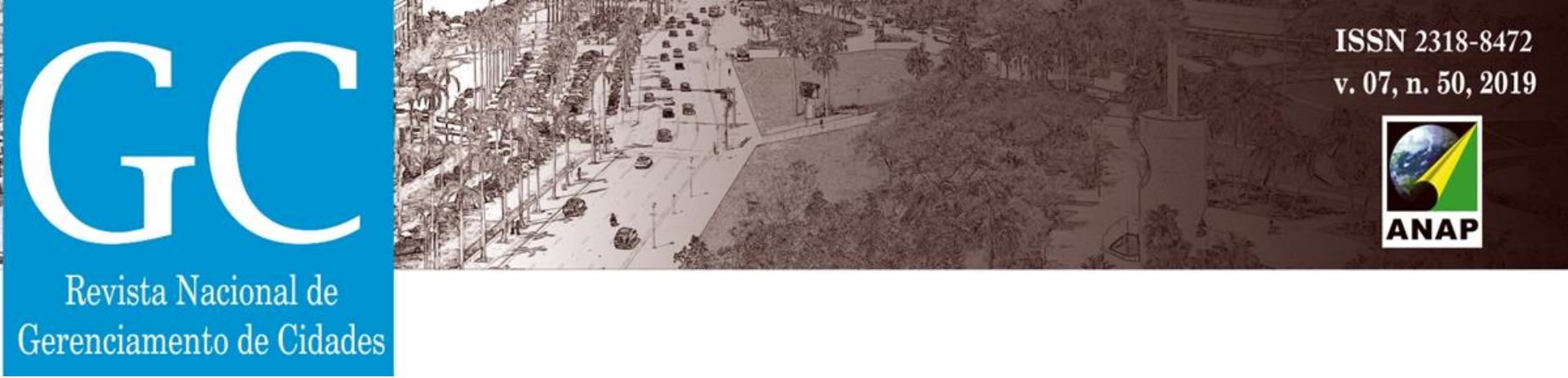

\section{INTRODUÇÃO}

O acelerado processo de urbanização sofrido pelos países latino-americanos pode ser observado nas grandes metrópoles desiguais, excludentes e com graves problemas ambientais. 0 colonialismo, o rentismo e o neoliberalismo vêm conformando uma organização territorial baseada no modelo centro-periferia estruturado em diversas escalas. Observa-se que, de maneira geral, os indicadores sociais pioram do centro para a periferia, porém, é importante não simplificar a análise e notar a complexidade e a diversidade do espaço produzido1. Tudo isso indica a necessidade de pesquisas que considerem a dimensão multiescalar da produção do espaço, uma vez que o território se constitui como um elemento fundamental na promoção de sociedades mais equitativas. As particularidades da produção do espaço latino-americano requerem um olhar próprio que considere as especificidades do nosso processo e da nossa cultura. Neste sentido, acredita-se que apesar dos processos de produção do espaço dos países latino-americanos apresentarem muitas semelhanças quando analisados em uma escala macro, existem diferenças que só podem ser percebidas a partir da escala micro. Assim, à medida que se aproxima da escala da rua e da travessa, as capacidades de resistência, os tempos e as singularidades de cada lugar se tornam mais reconhecíveis e distinguíveis nas espacialidades do cotidiano. Isso demonstra a necessidade de se avançar nos estudos realizados na "escala do cotidiano" que ajudem a perceber elementos de identidade no contexto periférico.

Acredita-se que a análise dos espaços livres públicos seria capaz de revelar as especificidades nos modos de apropriação da cidade, dependentes do contexto cultural de cada país. Frente a isto, este trabalho busca analisar os processos de produção e/ou apropriação de dois espaços livres públicos em países latino-americanos, a partir de dois estudos de caso, o primeiro caso em Quito / Equador, com a experiência do espaço cultural e parque criados pela Cooperativa de Vivienda Alianza Solidaria, e o segundo em São Paulo / Brasil, com a experiência do espaço cultural Quilombo da Parada. A partir destes exemplos buscamos identificar as particularidades do papel do espaço livre público como um ativador/aglutinador da organização social nestas comunidades. Baseando-se nestas experiências, busca-se articular generalidades e singularidades, cruzando leituras contextuais com informações coletadas em campo. Ao destacar as similaridades sem conceder uma explicação generalizante, permite-se que surjam bases para relacionar ambos casos como parte do quadro geral latino-americano. A partir dessas considerações busca-se demonstrar a relevância da discussão dos padrões urbanísticos de produção do espaço latino-americano, como importantes locais de ação social, econômica, política e cultural.

\footnotetext{
${ }^{1}$ Em São Paulo, por exemplo, as disparidades de renda entre os chefes de família mais pobres e os mais ricos se mantém e que a classe de renda baixa ou muito baixa se concentra nas áreas mais periféricas da metrópole. Isso não quer dizer que a periferia seja um bloco uniforme, pois há uma crescente heterogeneidade nas áreas periféricas de baixa renda. Elas se diferenciam consideravelmente segundo o rendimento, escolaridade, serviços, etc. (MARQUES E TORRES, 2000).
} 


\section{Revista Nacional de}

Gerenciamento de Cidades

\section{DESDE O MACRO: O PROCESSO DE URBANIZAÇÃO COMO UM POSSÍVEL INSTRUMENTO DE LEITURA DA CIDADE LATINO-AMERICANA}

Desde a segunda metade do século XX a América Latina é considerada uma região majoritariamente urbana (ONU-HABITAT, 2010). Este processo de urbanização é caracterizado por um intensa migração campo-cidade que em menos de 40 anos (1950-1990) faz com que a região sofra um giro rural-urbano. Neste período, a população que residia nas cidades saltou de $40 \%$ para $70 \%$, originando as grandes metrópoles latino-americanas (MONTERO, LAETITIA; GARCIA, 2017; ONU-HABITAT, 2011). Esta "explosão urbana” ou "hiper-urbanização" (MANUEL CASTELLS, 1973) fez com que as grandes cidades com mais de 1 milhão de habitantes ganhassem importância no continente, convertendo-se muitas vezes no retrato da cidade latino-americana.

Apesar de nossas cidades estarem associadas a ideia das grandes metrópoles subdesenvolvidas, sabemos que a cidade latino-americana abrange muitas ideias inerentes ao conceito de cidade. No entanto, há algo que nos une quando pensamos no contexto urbano? É possível falar em "cidade latino-americana"? Para Gorelik (2005) "seria absurdo tentar definir a cidade latinoamericana por meio de um ideal de representação de um conjunto de características a ela atribuídas". Embora sejam diversas e singulares, em linhas gerais pareceria possível construir esta identidade ao se recuperar a ideia do processo de urbanização latino-americano. Este processo teve alguns marcos importantes que imprimiram características comuns a estas cidades, como por exemplo: a colonização e a fundação das primeiras cidades; a independência e o período de modernização urbana; o início da industrialização e o surgimento das metrópoles e mais recentemente a globalização e o neoliberalismo que aprofundam as desigualdades, a segmentação social, o crescimento das periferias.

Outro debate que nos ajuda a pensar o processo de urbanização das cidades latino-americanas pode ser fundamentado a partir das contribuições trazidas por Quijano (2005) a respeito da colonialidade do poder, uma característica que se revela no processo histórico desenvolvido durante a colonização da América Latina. Nesta perspectiva, a América Latina teria sido fundamental para o estabelecimento de uma nova estrutura de poder mundial de caráter colonial/moderno, capitalista e eurocêntrico. Durante este período a América se converteu na primeira periferia do sistema-mundo, possibilitando a acumulação primitiva do capital (DUSSEL, 2005). Ainda, segundo Quijano (1978) "o processo de independência dos Estados na América Latina sem a descolonização da sociedade não pôde ser, não foi, um processo em direção ao desenvolvimento dos Estados-nação modernos, mas uma rearticulação da colonialidade do poder sobre novas bases institucionais". O autor afirma que a estrutura de poder na América Latina foi e ainda segue organizada sobre e ao redor do eixo colonial (QUIJANO, 1978).

Estas relações se perpetuam até a contemporaneidade e se revelam no espaço urbano, principalmente nas grandes cidades latino-americanas. Durante o século XX, as transformações 


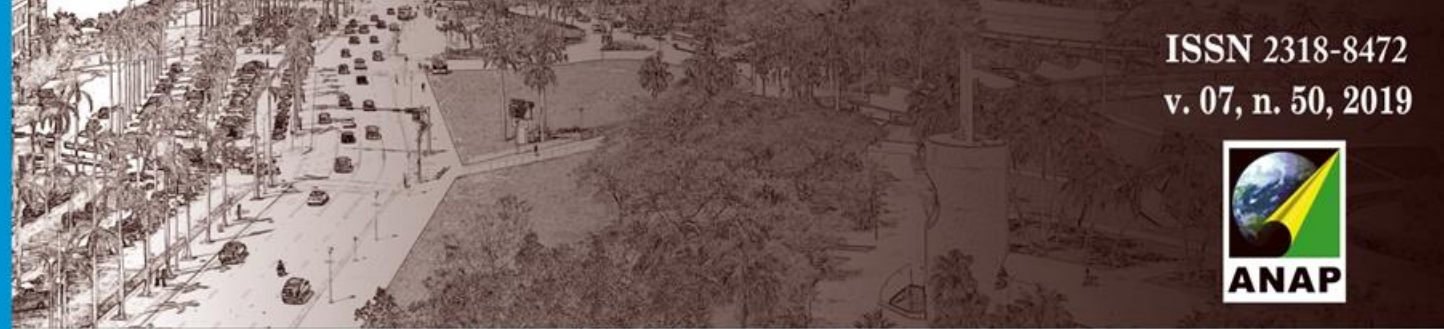

Revista Nacional de

Gerenciamento de Cidades

do sistema capitalista pelo neoliberalismo intensificaram estas características, em um processo iniciado a partir dos anos 1970, quando o ideal liberal foi retomado, se impondo como um "pensamento único" em resposta a crise mundial. Quando o receituário neoliberal chega aos países latino-americanos, imposto pelo Consenso de Washington, entre as décadas de 80 e 90, não só a economia é afetada. As implicações desta conjuntura nas cidades podem ser observadas na defesa de um urbanismo de caráter empresarial privatista que passa a ressignificar o planejamento e as intervenções urbanas que conformam assim a "cidade do pensamento único" (ARANTES, O.; VAINER, C.; MARICATO, E.2002). Este modelo de cidade favorece a sua privatização e a apropriação do espaço a partir da mercantilização da vida que contribuem para a consolidação de um padrão de segregação urbana cada vez mais desigual. Portanto, a chegada deste modelo na região, reforça o "sentido da colonização" nas cidades latino-americanas (PEREIRA, 2016).

Sassen (1991), Borja e Castells (1997), ao considerar o processo de globalização e a formação de um sistema mundial de cidades, afirmam que as metrópoles adquirem importância como cidades globais e se tornam cada vez mais estratégicas para o capital global. No entanto, esta ótica generalizadora não reconhece as particularidades de cada cidade frente à tendência homogeneizadora da globalização e do sistema capitalista. Queiroga (2002) aponta que apesar deste sistema parecer inquebrantável "aceleram-se as trocas e com elas, contraditoriamente, potencializam-se ações não previstas pela razão sistêmico-econômica, e estabelecem-se razões divergentes às ordens globais".

Portanto, a construção do processo de urbanização nos permite compreender que existem problemas comuns às nossas cidades e que é possível intercambiar soluções urbanas e ideias para enfrentar os problemas comuns. No entanto, é preciso reconhecer que apesar de existirem questões que nos unam e possibilitam o intercâmbio de experiências, existem diferenças tangíveis que revelam a existência de particularidades em cada cidade. Milton Santos (1977) ressalta que o lugar deve ser compreendido levando-se em conta a totalidade do processo e a realidade global, mas também precisa ser entendida através das diferenças. Quando Santos (1990) afirma que "a metrópole paulista só pode ser entendida no contexto de um país subdesenvolvido industrializado", o autor mostra a impossibilidade de abstrair o lugar do contexto, e que especificidades referentes a tempos e lugares diferentes são indispensáveis para sua compreensão. Por este motivo torna-se fundamental aprofundar nas experiências locais, identificando as relações estabelecidas com o entorno e compreender o papel de cada uma delas no contexto urbano. Assim, a análise dos fatos urbanos que consideram as particularidades históricas, políticas e socioculturais torna-se importante para a compreensão da paisagem latino-americana. Apesar das diferentes interpretações, percebemos que a identidade latinoamericana ainda é um tema em construção e que este movimento de aproximação e distanciamento, esta capacidade de olhar as relações do lugar para fora do lugar são imprescindíveis para entender a natureza destas cidades. 


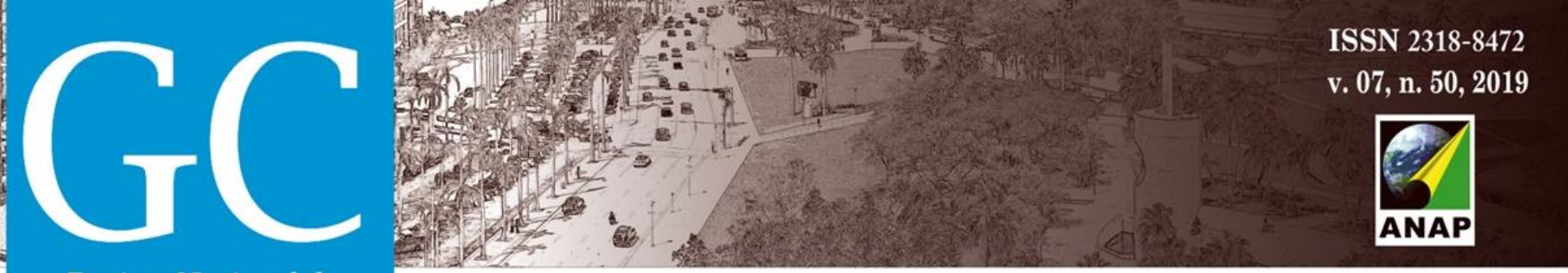

Revista Nacional de

Gerenciamento de Cidades

portanto, carregados de potencial transformador, característico da simultaneidade e heterogeneidade do urbano (QUEIROGA, BENFATTI, 2007). Tomando o conceito da "formação socioespacial"4 de Milton Santos (1977), entende-se que a configuração dos espaços livres, como maior suporte físico-material, pode ou não potencializar a esfera pública. Muitas vezes, especialmente nas periferias, essas dinâmicas se estabelecem em espaços não previstos para tal. De maneira geral, nota-se um descompasso entre como essa população se apropria dos espaços livres e como eles são tratados pelo Estado (tanto na criação quanto na manutenção).

Assim, entende-se que a categoria espaço livre público é capaz de possibilitar as mais variadas práticas cotidianas e apropriações públicas, e assim, apresentam maior associação à vida urbana, à esfera pública e à imagem da cidade, constituindo locais de conflitos e acordos, de permanência e de circulação, da biodiversidade e, mais importante, da sociodiversidade (QUEIROGA, 2012). É onde acontecem os eventos da vida pública, das manifestações políticas às principais festas religiosas, ocupando ruas, praças, praias, rios e orlas. São lugares de trocas sociais, de conversas entre vizinhos, de brincadeiras infantis, de jogos de futebol; abrangendo em distintos momentos, pessoas de variadas idades. Sendo assim, torna-se importante reconhecer qualidades na vida "em público" mesmo nas ações cotidianas não propositalmente políticas.

Esta vida pública cotidiana possui um grau de civilidade que se estabelece nos espaços livres públicos pode propiciar relações de afetividade pública, identidade coletiva e pertencimento importantes para seus moradores (QUEIROGA, 2012). Assim, os espaços livres públicos são como folhas em branco, abertos à diferentes formas de apropriação, ainda que improvisados e precários, constituem-se como o espaço primordial da esfera de vida pública, na escala local do cotidiano, e portanto constituem uma escala de análise micro que permite realçar as similaridades e destacar singularidades entre as cidades latino-americanas. Entende-se, que os espaços livres públicos podem revelar realidades político-culturais únicas que se relacionam com processos econômicos que se estabelecem em cada lugar, permitindo aproximações de maneira a proporcionar maior entendimento dos padrões de segregação urbana nas metrópoles.

O espaço do cotidiano, banal, corriqueiro, o espaço opaco ${ }^{5}$ de Milton Santos (1996) é comumente negligenciado pelas lógicas globais. No entanto, o interesse pelo cotidiano latino-

\footnotetext{
${ }^{4} \mathrm{O}$ espaço, como instância social, como conjunto indissociável entre o sistema de objetos e o sistema de ações, participa, com valor ativo dos conflitos entre diferentes atores sociais. "A evolução da formação social está condicionada pela organização do espaço, isto é, pelos dados que dependem diretamente da formação social atual, mas também das formações econômico-sociais permanentes" (SANTOS, 1977).

${ }^{5}$ São denominados territórios luminosos aqueles que acumulam densidades técnicas e informacionais e, portanto, se tornam mais aptos a atrair atividades econômicas, capitais, tecnologia e organização. Os territórios em que estas características não estão presentes são chamados de territórios opacos (SANTOS,1996).
} 


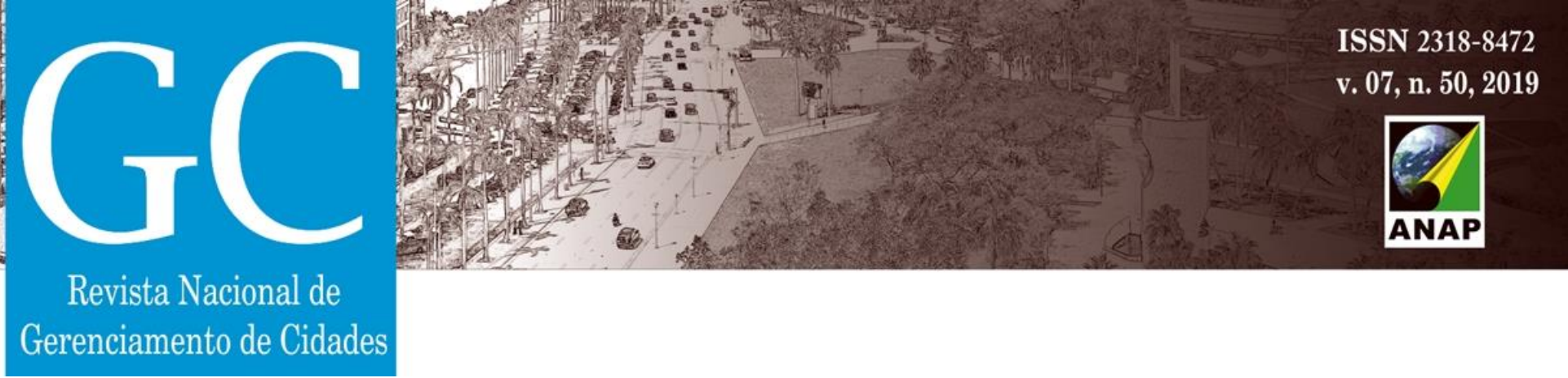

americano surge neste trabalho pois acredita-se que a vida cotidiana forma a cidade $^{6}$ e a recíproca é verdadeira. O cotidiano e a esfera pública estabelecem formas variadas de apropriação dos espaços livres, alterando de acordo com inúmeros elementos e fenômenos tais como padrões culturais, grupos sociais, clima, dia e horário, programação de eventos, inserção urbana, entorno edificado, condições de segurança entre outros. Além disso, a esfera do cotidiano corresponde, em termos espaciais, ao que Lefebvre (2006) em sua tríade espacial, denominou "espaço percebido": o espaço da prática social, o espaço dos sentidos, da produção e da reprodução, do trabalho e do lazer, definido, em suma, pela vida cotidiana.

As formas de apropriação pública do espaço livre definem vínculos sociais de identidade, solidariedade e ação comunicativa, e por isso, seus condicionantes e repercussões são singulares. Os costumes, hábitos, comportamentos, normas e tendências locais estão diretamente relacionados aos padrões culturais. Sendo assim, a partir dos elementos e fenômenos presentes nos espaços livres, pode-se compreender as relações entre apropriações públicas do cotidiano que ali se estabelecem e padrões culturais característicos de cada lugar, que se manifestam espacialmente nas formas materiais e simbólicas. A cultura é herança, mas também reaprendizado entre as profundas relações entre o homem e seu meio (SANTOS, 1996). Portanto, não basta a um "espaço livre" possuir uma forte imagem pública para que efetivamente possa ser caracterizado como praça; para tanto é necessário constituir-se num lugar propiciador do encontro na esfera de vida pública, potencializador da vida ativa e/ou da razão comunicativa.

Outro elemento a ser considerado na análise urbana é suporte biofísico. Além deste elemento configurar a paisagem, ele pode condicionar a urbanização e impactar na apropriação cotidianas dos espaços livres nas cidades. Subir e descer morros, conversar com vizinhos em "escadões", lavar roupas em córregos, cuidar da horta ou do jardim são práticas comuns principalmente em tecidos urbanos habitados pelos pobres. As principais estruturas físico-territoriais se revelam na constituição formal dos espaços livres e construídos, e determinam em diferentes intensidades, as normas e práticas de produção e apropriação do espaço urbano contemporâneo.

Reitera-se a natureza da cidade, essencialmente pública e seu potencial pedagógico e político, no caso contribuindo para a percepção da natureza segunda ${ }^{7}$. Neste sentido, a paisagem se revela como uma grande aliada para a sensibilização de agentes sociais sobre a importância da presença de elementos e sistemas naturais nos meios mais alterados pelo processo social.

\footnotetext{
6 "A própria cidade é uma obra, e esta característica contrasta com a orientação irreversível na direção do dinheiro, na direção do comércio, na direção das trocas, na direção dos produtos. Com efeito, a obra é valor de uso e o produto é valor de troca. O uso principal da cidade, isto é, das ruas e das praças, dos edifícios e dos monumentos, é a festa (que consome improdutivamente, sem nenhuma outra vantagem além do prazer e do prestígio, enormes riquezas em objetos e dinheiro)" (LEFEBVRE, 1991).

7 "Natureza e Espaço são sinônimos, desde que se considere a Natureza como uma natureza transformada, uma Segunda Natureza, como Marx a chamou" (SANTOS, 1977).
} 


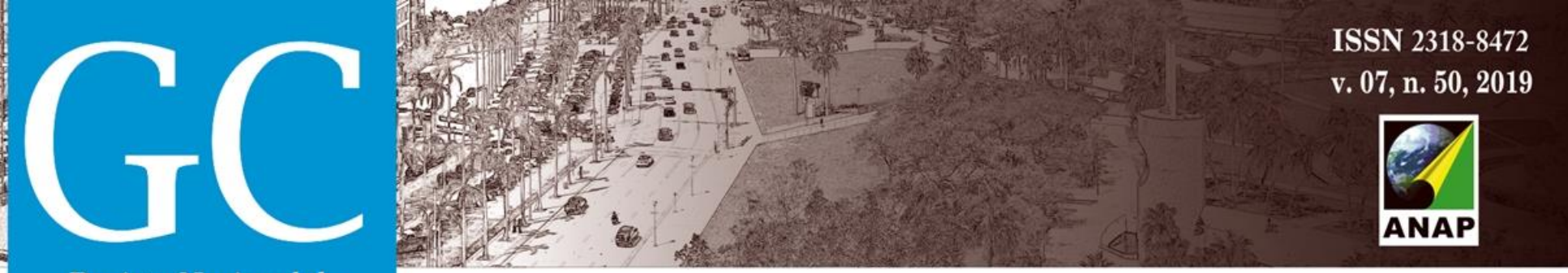

Revista Nacional de

Gerenciamento de Cidades

Assim, existem particularidades que surgem da constituição ambiental, dos processos históricos e das realidades políticas e sócio-culturais que se revelam únicas quando nos aproximamos no recorte do bairro e da rua, sem perder a relação com o lugar. Portanto, a perspectiva de se considerar a natureza enquanto lugar público pode ensejar revisões pertinentes das normas e práticas de produção e apropriação do espaço urbano contemporâneo em relação às dinâmicas e capacidades do suporte biofísico.

\section{DESDE O MICRO: OLHARES SOBRE A CIDADE LATINO-AMERICANA A PARTIR DAS EXPERIÊNCIAS DE QUITO E SÃO PAULO}

\section{Quito - Equador: a Cooperativa de Vivienda Aliança Solidária}

A Cooperativa de Vivienda Alianza Solidaria - COOVIAS, fundada no ano 2000, está situada na periferia sul da cidade de Quito é um dos resultados das lutas pela moradia na capital do país. Seus idealizadores tinham a ideia de empreender um programa de desenvolvimento comunitário enfocado em resgatar valores ambientais e culturais. Assim surge o projeto de habitação de interesse social Villa Solidaridad ${ }^{8}$, com a proposta de:

\footnotetext{
...crear un nuevo modo de vida, con una comunidad participativa, consciente y solidaria, ubicada en un territorio debidamente planificado, con formas de poder y control que lleven a constituir una fuerza social con una identidad propia, basada en el trabajo, el respeto de la diversidad, la democracia, la iniciativa individual y colectiva, la ayuda mutua y la autogestión (COOVIAS, 2012b, s.p.)
}

O terreno adquirido pela cooperativa tinha aproximadamente seis hectares, situado no eixo de expansão sul da cidade, era uma área tradicionalmente industrial, mas estava dentro do perímetro delimitado pelo Plan Quitumbe ${ }^{9}$, um importante plano para o desenvolvimento urbano da região. A estrutura físico-territorial da região se destacava pela presença de duas grandes quebradas ${ }^{10}$ (talvegues) Ortega e El Carmen, uma característica que trazia algumas dificuldades para a implantação do projeto (COOVIAS, 2012a).

\footnotetext{
${ }^{8}$ Villa Solidaridad foi um projeto cooperativo de moradias no sul da cidade de Quito que visava atender a mais de 3.000 famílias (COOVIAS, 2012a, p.23).

${ }^{9}$ O Plan Quitumbe foi um projeto de desenvolvimento urbano idealizado pelo município de Quito para região sul da cidade com o objetivo de criar uma nova centralidade para a cidade incorporando novos usos como equipamentos públicos para educação, cultura, recreação, gestão pública, assistência social e saúde junto com a produção de moradia. A partir de 2005 são definidos os parâmetros urbanísticos, os espaços verdes e a futura a localização dos equipamentos públicos e nos anos seguintes, importantes obras de infraestrutura foram construídas no entorno, entre elas o Parque Las Cuadras (2007), o Terminal Terrestre Quitumbe (2008) e mais recentemente a Plataforma Gubernamental de Desarrollo Social (2018).

10 O Equador está localizado no chamado cinturão de fogo do Pacífico, por este motivo apresenta uma grande quantidade de vulcões em seu território, gerando uma morfologia marcada pela presença de talvegues (quebradas) produto dos fluxos sedimentares das erupções vulcânicas (PELTRE, 1989).
} 


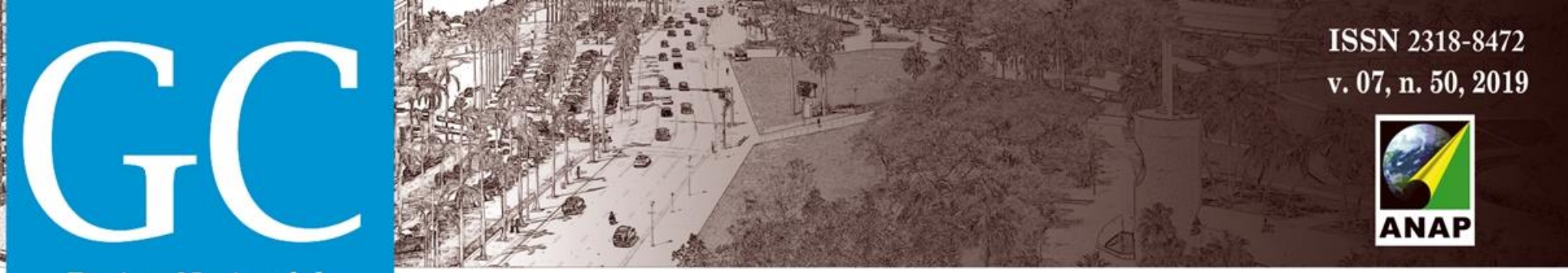

Revista Nacional de

Gerenciamento de Cidades

Uma vez comprado o terreno, a cooperativa deu início ao processo participativo com o objetivo de definir a implantação do projeto. Foram realizadas atividades de formação e conscientização, inspiradas nas experiências do educador Paulo Freire, buscando promover a "transformação dos associados a partir das suas próprias atitudes, crenças, paradigmas, formas de pensar e atuar" (LÓPEZ, 2010, p.73). Nestes encontros eram debatidos temas como comunidade, interação de vizinhos, segurança comunitária, resolução de conflitos e cultura do diálogo com o objetivo de provocar uma atitude crítica e um posicionamento consciente frente ao problema da habitação, sempre apresentado como algo mais além da construção de casas, que deveria considerar o meio natural em torno às moradias, era "necessário discutir o hábitat" (MELO, sem data [b]).

Todo o processo de urbanização se deu a partir do modelo cooperativo e da autogestão. Assim, para a implantação de infraestrutura foram assinados convênios entre a cooperativa e o município que previam a corresponsabilidade dos custos da obra. Os projetos de parcelamento e arquitetônico e a construção das casas estiveram a cargo de um escritório de arquitetura, mas as decisões eram tomadas pela unidade gestora, formada por sócios da cooperativa e profissionais do escritório. Além disso, a cooperativa organizou formação de pedreiros entre seus sócios, pois muitos deles estavam desempregados devido a crise política e econômica que o país enfrentava. Desta maneira, buscavam gerar empregos na própria comunidade e gerar um sentimento de pertencimento aos futuros moradores.

Todo este processo contribuiu para que os moradores tomassem importantes decisões ao longo do processo. Uma importante decisão que mudaria completamente o rumo do projeto foi escolha pela recuperação e preservação das quebradas para a implantação de um parque linear. Esta decisão é entendida como o resultado de processo de conscientização ambiental, mas principalmente como o desejo de promover um habitat de qualidade na periferia. Ao recuperar e proteger as quebradas, os moradores rompiam com as práticas comumente utilizadas em Quito desde o período colonial e reafirmavam a cultura ancestral andina ao reconhecer homem e natureza como parte de um único sistema, uma ideia ainda muito presente nesta população que a pouco tempo havia deixado o campo em busca de melhores condições de vida na capital.

Assim, a presença das duas quebradas, que no momento de reconhecimento do terreno havia gerado uma decepção generalizada entre os associados, tornou-se motivo de orgulho dos cooperados. A imagem da quebrada construída desde o imaginário popular como depósito de lixo e esgoto a céu aberto, onde apenas famílias pobres deveriam resignar-se a viver perto, foi pouco a pouco sendo rompida. Esta ideia havia sido construída desde o período colonial, e evidenciava "a discriminação, o desprezo e o medo da natureza" (MELO, sem data[c]). É a partir deste período que as quebradas passaram a ser preenchidas com o objetivo de promover a expansão urbana. Em nome da modernidade, muitas quebradas de Quito foram (e ainda são) preenchidas com resíduos compactados para a construção de ruas, parques e moradias. Assim, as quebradas foram sendo paulatinamente apagadas em nome do progresso e do desenvolvimento. Portanto, quando a comunidade decide por meio de assembleia recuperar os 


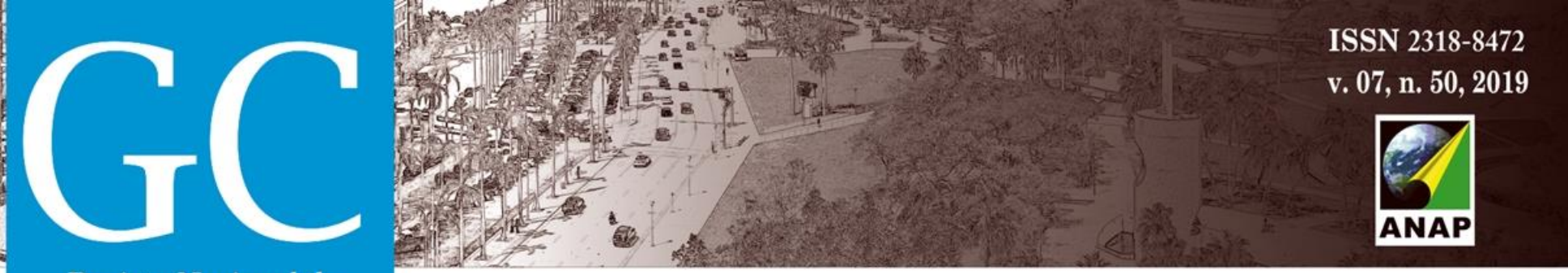

Revista Nacional de

Gerenciamento de Cidades

talvegues e implantar o parque ecológico rompe-se com um processo histórico predatório, transformando o aparente "problema" em oportunidade.

A implantação do parque ecológico durou 10 anos e foi organizado em três etapas: limpeza, recuperação e construção. Durante os três primeiros anos de limpeza, os moradores tiraram dez toneladas de lixo do fundo e das encostas das quebradas (MELO, sem data[c]). Todo processo foi realizado a partir do trabalho comunitário ancestral por meio da ming ${ }^{11}$. Portanto, os valores ancestrais, baseados em ações de reciprocidade e solidariedade, foram recuperados para promover a recuperação ambiental das quebradas Ortega e El Carmen. As mingas eram realizadas todos os domingos e eram abertas para todas as famílias. Neste momento, as hierarquias eram rompidas, participaram do trabalho presidentes, diretores e associados. Esta dinâmica reforçou as relações horizontais "criando laços de solidariedade que distinguiram essa experiência de outras" (COOVIAS, 2012a, p.54). Durante este processo as pessoas se envolveram com o problema, entenderam a situação social e cresceram politicamente dentro de uma "experiência difícil e sacrificada, mas muito enriquecedora e esclarecedora" (MELO, sem data[c]).

As mingas continuaram durante a etapa de recuperação e em pouco tempo as quebradas sujas e contaminadas se converteram em espaços limpos e de qualidade para o bairro e para a cidade. A recuperação não seguiu nenhum estudo de manejo ambiental ou geológico, aconteceu de maneira empírica a partir dos conhecimentos práticos da comunidade. O corredor ambiental criado protegeu as nascentes e evitou as enchentes na região. A experiência foi reconhecida pelo município de Quito em 2002, que passou a apoiar a iniciativa por meio da instituição "Vida para Quito"12, a partir da assinatura de um convênio para descontaminação do curso d'água, plantio de árvores nativas através de um programa educativo, construção de jardins, criação de uma estação de tratamento de água e a construção de espaços comunitários de esporte e lazer (COOVIAS, 2012a). Ainda que as ações do governo não foram implementar em sua totalidade, esta iniciativa demonstrou como uma ação local é capaz de incidir em políticas públicas.

$\mathrm{Na}$ etapa de construção do parque, foram implementados 6 quilômetros de ciclovias, quiosques, áreas verdes, pomares, plataformas para semear jardins nas encostas da quebrada, caminhos ecológicos, parque infantis e pontes (MELO, sem data[c]). A partir de um plano de educação ambiental promovido pelo município e pela cooperativa foram plantadas aproximadamente

\footnotetext{
${ }^{11}$ A minga ('minka' em kichwa, idioma indígena) é parte das culturas ancestrais e segue presente na sociedade equatoriana. Trata-se de uma maneira de organização do trabalho comunitário para intervenção nos territórios (construção de canais de abastecimento de água, calçamento de ruas, etc.). Tradicionalmente a minga é um poderoso ritual cultural e cerimonial de reunião comunitária, um espaço de intercâmbio de normas socioculturais, que sintetiza a importância do trabalho dentro da cultura andina, visto como um elemento fundamental para garantir o bem estar individual, familiar e coletivo.

${ }^{12}$ A instituição "Vida para Quito" foi uma corporação pública de saúde ambiental adjunta ao município de Quito que se encarregava de temas ambientais da cidade.
} 


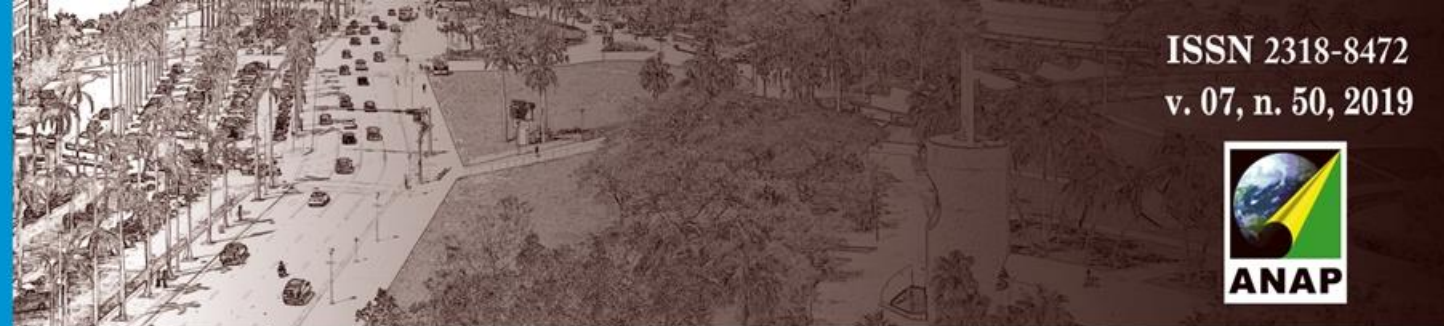

Revista Nacional de

Gerenciamento de Cidades

4000 mudas de árvores, que contribuíram para o reflorestamento do setor, ação realizada com o apoio de estudantes de colégios dos bairros próximos. Além disso, foram construídos 800 metros de caminhos ecológicos e as nascentes foram protegidas.

Estas ações comunitárias incentivaram outras cooperativas e o poder público, influenciando a criação do Parque Lineal del Rio Machángara em 2004 pelo município de Quito, com 30 quilômetros de extensão dedicados a preservação e proteção das quebradas do principal rio da cidade e em 2008 o município adotou a política de recuperação e tratamento das quebradas, representando um importante avanço no manejo ambiental destes ecossistemas tão importantes para a cidade. O Município de Quito reconheceu o trabalho da COOVIAS por meio da Distinção Ambiental Metropolitana Quito Sostenible em 2016 (DMQ, 2017). E atualmente, são promovidos diversos eventos culturais, para a reunião comunitária, demonstrando uma grande preocupação com o futuro da cooperativa e da formação de uma juventude ativa que mantenha o projeto.

\section{São Paulo - Brasil: espaço cultural Quilombo da Parada}

O Quilombo da Parada foi fundado em 2009 por algumas famílias de negros pobres da cidade de São Paulo que compraram o terreno localizado no distrito do Jaraguá, extremo da zona noroeste da capital. A partir de uma leitura ampla das principais estruturas físico-territoriais da região, destacam-se a grande quantidade de córregos e nascentes, e a potente Serra da Cantareira com a qual o Quilombo faz divisa.

Essa área também abrange o entorno do trecho norte do Rodoanel Mário Covas, que começou a ser construído em 2012, após cerca de oito anos de controvérsias entre moradores, ambientalistas e poder público. A área configura-se como um espaço urbano de distintos interesses e fragilidades, convertendo-se em objeto frequente de discussões no meio acadêmico e na sociedade em geral, resultando diversas vezes em processos jurídicos. A via em construção se estabelece como barreira, como cicatriz urbana que fragmenta a paisagem, e com isso, 0 ecossistema e as dinâmicas sócio-espaciais existentes.

Nota-se, assim, a definição de dois tecidos urbanos: a sul do Rodoanel, o bairro periférico precário, porém consolidado, e a norte a área do Quilombo, marcada pela inserção na mata primária, de baixa densidade habitacional e falta de infraestrutura básica.

O contexto urbano do Jaraguá é de contradições: altas densidades habitacionais e relevo movimentado, violência e sensibilidade, capital e pessoas, remanescentes importantes de mata primária e grandes estruturas impactantes como Rodoanel, piscinões e pedreiras. É também espaço de ação popular e disputas por moradia, ocupações e conjuntos habitacionais da Companhia de Desenvolvimento Habitacional e Urbano - CDHU que despejam seu esgoto nos córregos, e riqueza de recursos hídricos (atualmente comprometidos), tendência 


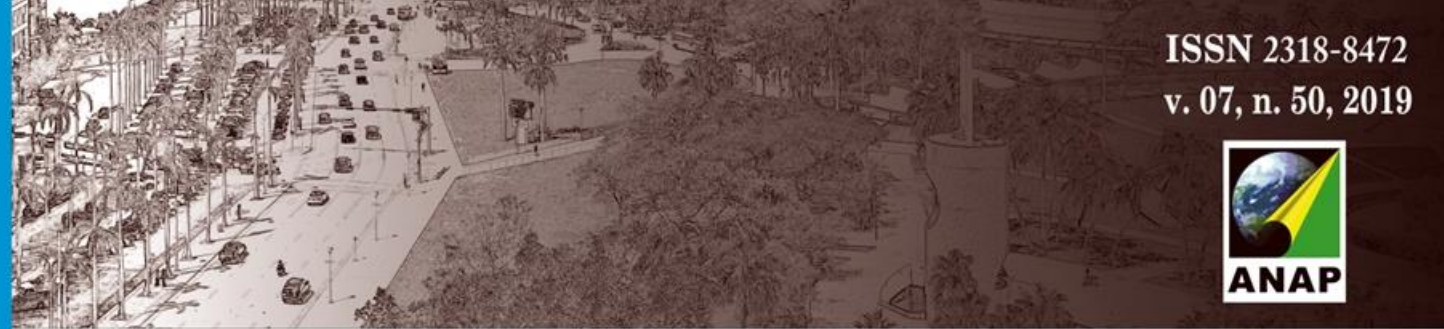

Revista Nacional de

Gerenciamento de Cidades

homogeneizadora que se manifesta na desigualdade social e produção cultural rica com atitudes criativas nas espacialidades do cotidiano que caracterizam a "identidade noroeste". Nas franjas das zonas Norte e Sul, a urbanização é fragmentada e o acesso é difícil. Pode-se dizer que natureza representa, para muitos, um incômodo principalmente pela ausência dos serviços públicos.

Na área do Quilombo da Parada, alguns dos principais conflitos sócio-ambientais identificados são: fragmentação do ecossistema, falta de acessibilidade física, degradação decorrente do uso indevido de recursos naturais, erosão do solo e ocupação irregular. O dia a dia dos moradores demanda o deslocamento à pé até o bairro para acesso a serviços, comércios e instituições, além da coleta de lixo e transporte público. Por outro lado, tal situação de "isolamento" (que será intensificada com a construção do Rodoanel), permite um contato maior com as dinâmicas ambientais proeminentes e um percurso nas vias orgânicas, estreitas e sem pavimentação repleto de perspectivas e mirantes que reafirmam a identidade a partir da paisagem lida e construída - e delimitada por marcos importantes: de um lado a Serra da Cantareira e do outro o Pico do Jaraguá. "Aqui não tem saneamento básico nem energia elétrica regularizada. Transporte? Só lá embaixo", fala de Juliana, fundadora do projeto cultural no Quintal do Quilombo da Parada.

Apesar do nome ser mantido, o Quilombo nunca foi de fato lugar de moradia, configurando-se basicamente como um espaço cultural de resistência (ou lugar de "contra-cultura") ligado a movimentos sociais que desenvolve diversas atividades relacionadas à identidade negra com a população local, especialmente crianças e adolescentes. Aulas de danças populares, literatura afro-brasileira e capoeira são algumas. A maioria dessas atividades é realizada nos espaços livres do entorno - campinhos ou quintais - reafirmando a importância do lugar e das dinâmicas ambientais proeminentes. Outras apropriações que se estabelecem nos espaços livres do Quilombo são as hortas comunitárias e composteiras criadas pelos moradores como forma de reconhecimento e contato com processos naturais (cultura de hortaliças) e processos sociais no cotidiano (organização comunitária).

Na tentativa de potencializar a vida pública e conectar as dinâmicas sociais e ambientais fragmentadas daquele tecido, alunos da disciplina Espaços Livres Públicos Coletivos Urbanos, do curso de pós-graduação da Faculdade de Arquitetura e Urbanismo da Universidade de São Paulo (FAUUSP) juntamente com os frequentadores do Quilombo propuseram que se estabelecessem diálogos com as escolas do bairro e realizassem encontros de formação entre os educadores e grupos/coletivos atuantes no território. A partir desses encontros, espera-se elaborar um manual de horticultura comunitária e reconhecimento do trajeto entre os dois lugares (bairro e quilombo), identificando pontos onde possam ser implantadas as hortas. As "hortas de guerrilha", como denominadas pelo grupo, põem em evidência o papel de resistência de agentes locais na produção da paisagem. 


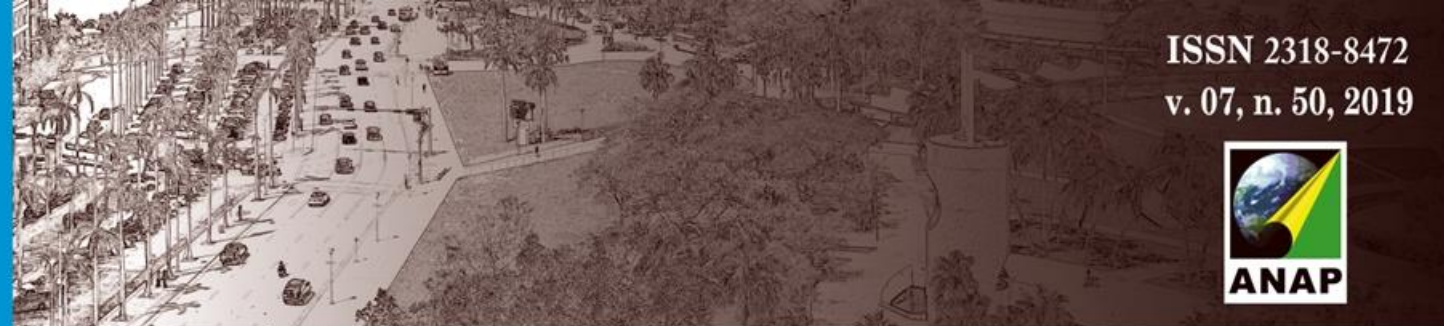

Revista Nacional de

Gerenciamento de Cidades

No bairro, as hortas possibilitam melhor utilização e qualificação de espaços e estimulam trocas e laços comunitários - negociação, construção e manutenção. No caminho de subida para o Quilombo, as hortas reforçam lugares de observação e leitura da paisagem natural e construída, e afirmam o papel ativo do morador da região na transformação da cidade. No Quilombo, as hortas já fortalecem as relações entre o meio ambiente e a comunidade e, principalmente, criam espaços de borda, indicando limites para a expansão da urbanização.

Assim, através das apropriações cotidianas nota-se fortes vínculos dos frequentadores do Quilombo com os espaços livres do entorno. As vistas possibilitadas pela cota alta do relevo acidentado e a vegetação proeminente são determinantes no cotidiano daquelas pessoas. A partir do entendimento das possibilidades paisagísticas do lugar desde o ponto de vista de quem ali vive, da consciência de cidadania e do desejo por uma convivência mais digna no espaço urbano, as "hortas de guerrilha" ampliam as possibilidades do lugar. Podem ser consideradas como uma tática "improvisada" auto-empreendida capaz de subverter imposições e controles diversos. Elas contribuem para a transposição e permeabilidade nos âmbitos material, social e simbólico do eixo do Rodoanel, repercutindo na re-conexão das dinâmicas da paisagem e no cotidiano das pessoas.

\section{Considerações finais}

Quando Santos (1996) define os "territórios opacos e territórios luminosos" percebe-se que não há uma trajetória única para as grandes metrópoles no processo de globalização. Existem peculiaridades que surgem da constituição histórica própria mas está associada a um sistema hegemônico que impõe lógicas que serão realizadas de maneiras diferentes em cada território. Nesse sentido, Morin (2015) afirma que a complexidade compreende também incertezas, indeterminações, fenômenos aleatórios. Assim, entende-se que entre o opaco e o luminoso há uma gradação que se apresenta espacialmente no cotidiano e na paisagem urbana, tanto em formas materiais como em formas sociais e simbólicas.

$\mathrm{Na}$ escala macro percebemos que existem semelhanças no contexto latino-americano que permitem paralelismos entre os estudos de caso: países subdesenvolvidos, marcados por processo de metropolização e periferização, com ocupação definida por uma marcante estrutura físico territorial, população pobre. No entanto, entendemos que as aproximações ao território a partir dos espaços livres permitem identificar como estes processos se estabelecem em cada lugar, influenciado por realidades culturais únicas, possibilitando alcançar maior entendimento das formas de apropriação, como vemos nos casos estudados.

Em ambas experiências, diante da compreensão da produção e das relações dos espaços livres e suas apropriações resultantes de sua interface com o suporte biofísico, padrões culturais, realidades políticas e processos econômicos foi possível, em diferentes níveis, estabelecer proposições, contribuir para políticas públicas para qualificar o meio urbano e avançar no debate 


\section{Revista Nacional de}

Gerenciamento de Cidades

das cidades latino-americanas. Em Quito, o olhar dos moradores sobre sua condição de moradia foi ampliada para a construção de um habitat, que se desdobrou na construção do parque linear e na preservação das "quebradas" ativando costumes ancestrais e buscando uma melhor relação com a natureza, um processo realizado pela comunidade e com a posterior participação do poder público. Em São Paulo, o olhar de fora da academia, em colaboração com os frequentadores do Quilombo, originou a proposta das "hortas de guerrilha" como conectoras da paisagem. Independentemente dos resultados, percebemos que houve o reconhecimento dos espaços livres e da natureza como potenciais facilitadores da apropriação comunitária/pública, principalmente em espaços vulneráveis socialmente. Apesar dos processos comuns identificados na escala macro, é fundamental reconhecer a diversidade urbana latinoamericana, legitimando as particularidades e as oportunidades de cada caso, junto com a população envolvida em cada lugar.

\section{REFERÊNCIAS BIBLIOGRÁFICAS}

ARANTES, O.; VAINER, C.; MARICATO, E. A cidade do pensamento único. 3. ed. São Paulo: Editora Vozes, 2002.

BORJA, J.; CASTELLS, M. Local y Global. La gestión de las ciudades en la era de la información. Madrid, Taurus, 1997.

CASTELLS, M. Imperialismo y urbanizacion en america latina. Barcelona: Editora Gili, 1973.

CERTEAU, M. A invenção do cotidiano: 1, Artes de fazer. Petrópolis: Vozes, 1990.

COOVIAS. Cooperativa de Vivienda Alianza Solidaria. La Cooperativa de Vivienda Alianza Solidaria 10 años de historia: procesos y aprendizajes 1990-2010. Tomo I [Libro] Archivo: COOVIAS. Quito, 2012a.

COOVIAS. Cooperativa de Vivienda Alianza Solidaria. La Cooperativa de Vivienda Alianza Solidaria 10 años de historia: procesos y aprendizajes 1990-2010. Tomo 3 Planes y Propuestas Solidaridad - Coovias [Libro] Archivo: COOVIAS -FEDAEPS. Quito, 2012b.

COOVIAS. Cooperativa de Vivienda Alianza Solidaria. La Cooperativa de Vivienda Alianza Solidaria 10 años de historia: procesos y aprendizajes 1990-2010. Tomo 6 Revista y Trípticos - Coovias [Libro] Archivo: COOVIAS -FEDAEPS. Quito, 2012c.

DMQ. Secretaría de Ambiente Municipal de Quito Distinción Ambiental Metropolitana Quito Sostenible. 2017. Disponível http://www.quitoambiente.gob.ec/ambiente/images/Secretaria_Ambiente/Buenas_Practicas_Ambientales/distinci on/informacion_DAM_QS_2017.pdf [Accessed 2 Oct. 2018].

DUSSEL, E. Europa , modernidade e eurocentrismo. CLACSO, Consejo Latinoamericano de Ciencias Sociales, p. 11, 2005.

GORELIK, A. A produção da "cidade latino-americana". Tempo Social revista de sociologia da USP, São Paulo, v.17, n.1, p.111-133, 2005. 
LEFEBVRE, H. A produção do espaço. Trad. Doralice Barros Pereira e Sérgio Martins (do original: La production de l'espace . 4e éd. Paris: Éditions Anthropos, 2000). Primeira versão: 2006.

LEFEBVRE, H. O direito à cidade. São Paulo: Centauro, 1991.

LOPEZ, S. El Rol de la Formación en la Construcción de Comunidad Participativas y Autogestionarias para el Buen Vivir, aplicado en el Proyecto Habitacional Alpallacta de la Cooperativa de Vivienda Alianza Solidaria. Graduação. Universidad Politécnica Salesiana Sede Quito, 2014.

MAGNOLI, M. Espaços livres e urbanização: uma introdução a aspectos da paisagem metropolitana. Tese (Livredocência - Área de Concentração: Paisagem e Ambiente) - Faculdade de Arquitetura e Urbanismo, Universidade de São Paulo, São Paulo, 1982.

MARQUES, E.; TORRES, H. As transformações recentes em São Paulo e o debate das cidades globais. São Paulo: Novos Estudos (CEBRAP), 2000.

MAUTNER, Y. A periferia como fronteira de expansão do capital. In: DEAK, C.; SCHIFFER, S. (orgs.). O processo de urbanização no Brasil. São Paulo: Edusp, 2004.

MELO, F. Autogestión Comunitaria para el Buen Vivir. Una experiencia de economia solidaria para la construcción de habitat, comunidad y vivienda en entornos urbano populares. Quito: Presidencia Coovias, sem data[b].

MELO, F. Construyendo Hábitat Comunitario y Autogestionario: medio ambiente, espacio público, comunidad y vivienda. Una experiencia de construcción social y cooperativa de hábitat popular en el Sur de Quito. Sem data[c].

MELO, F. Resumen Ejecutivo. Nuestra Propuesta Cooperativa - I Parte. Quito: Presidencia Coovias, sem data[a].

MONTERO, L.; GARCIA, J. Panorama multidimensional del desarrollo urbano en América Latina y el Caribe. [S.I: s.n.], 2017.

MORIN, Edgar. Introdução ao Pensamento Complexo. Tradução: Eliane Lisboa. 5. ed. Porto Alegre: Sulina, 2015.

ONU-HABITAT. Estado de las Ciudades de America Latina e el Caribe. [S.I: s.n.], 2011.

ONU-HABITAT. Estado de las ciudades de America Latina y el Caribe. Rio de Janeiro - Brasil: ONU-HABITAT, 2010.

PELTRE, P. Quebradas y riesgos naturales en Quito, período 1900-1988. Riesgos Naturales en Quito, Lahares, aluviones y derrumbes del Pichincha y del Cotopaxi, in Estudios de Geografía, 2, 45-91, 1989.

PEREIRA X. P. C. Processos e problemas na urbanização da América Latina: teoria e história. Territorios, Urbanização da America Latina importancia da urbanização planejada, v. 18, n. 34, p. 35-58, 2016.

QUEIROGA, E. A megalópole e a praça: o espaço entre a razão de dominação e razão comunicativa. Tese (Doutorado em Arquitetura e Urbanismo) - Faculdade de Arquitetura e Urbanismo, Universidade de São Paulo, São Paulo, 2002.

QUEIROGA, E. Dimensões públicas do espaço contemporâneo: resistências e transformações de territórios, paisagens e lugares urbanos brasileiros. Tese (Livre Docência - Área de Concentração: Paisagem e Ambiente) Faculdade de Arquitetura e Urbanismo, Universidade de São Paulo, São Paulo, 2012. 

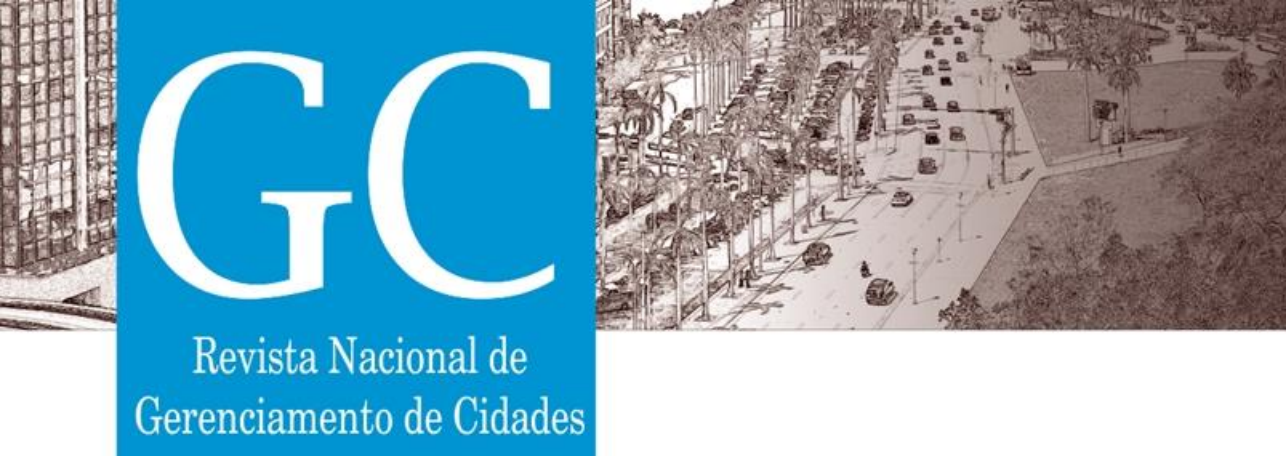

Figura 03: Parte do distrito do Jaraguá com construção do Rodoanel e consequente fragmentação do território. Percurso dos pedestres do Quilombo da Parada até a Escola Parada de Taipas.

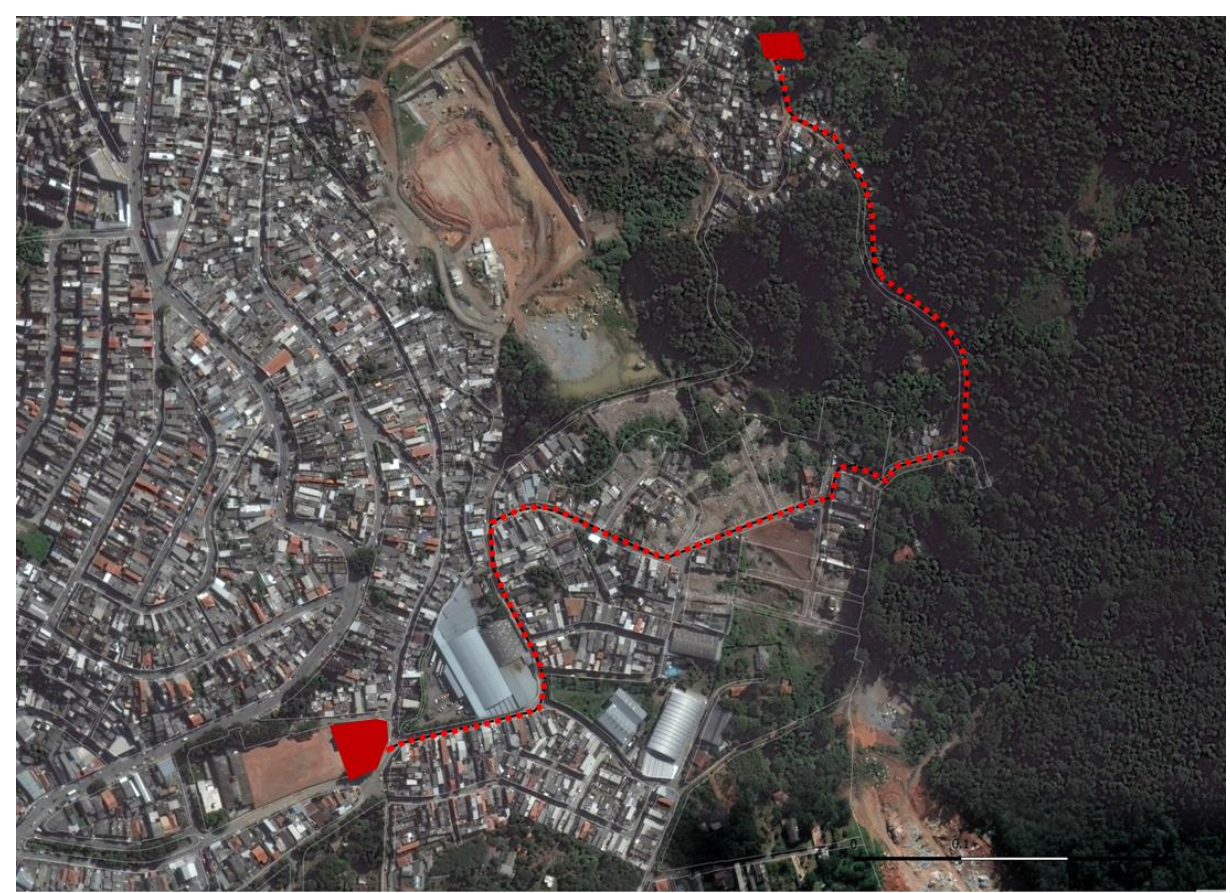

Fonte: IMAGEM SATÉLITE GOOGLE EARTH, 2018, COM INTERVENÇÃO DE ISABELA LEMOS.

Figura 04: Visita ao Quilombo da Parada, distrito do Jaraguá. São Paulo, Brasil.

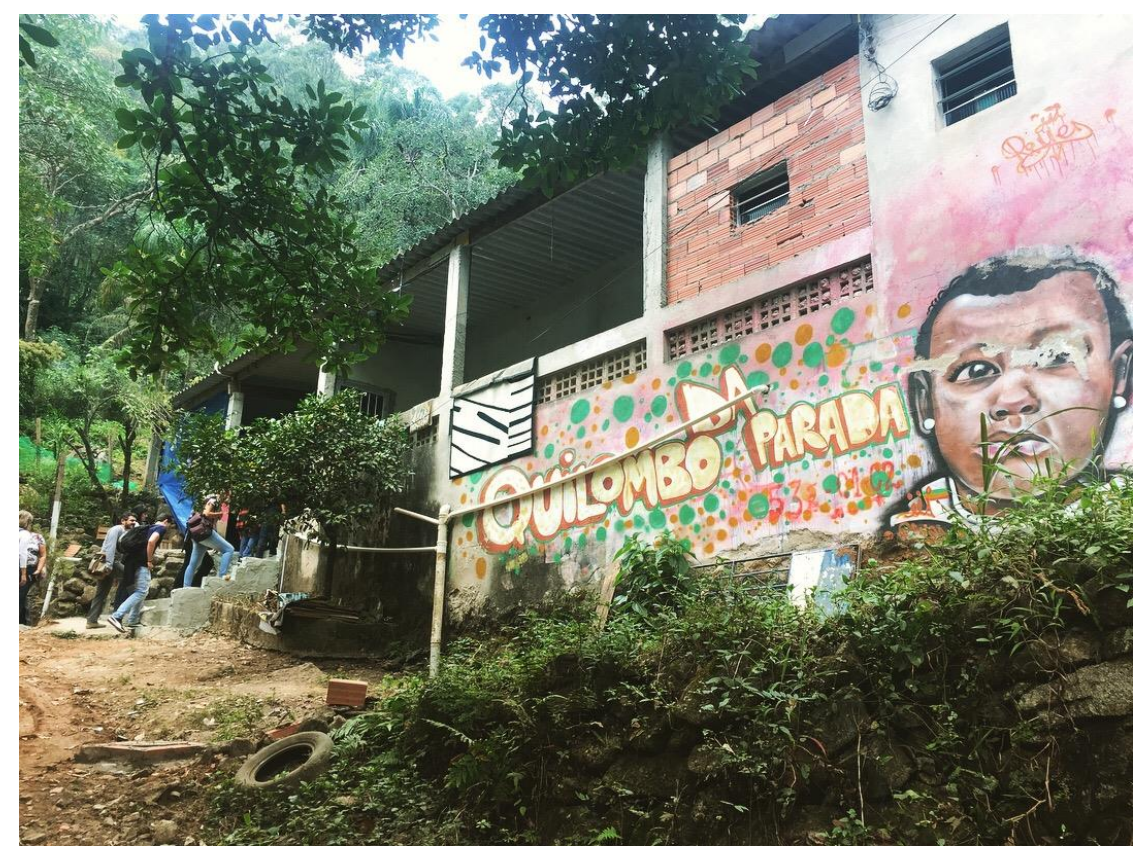

FONTE: ISABELA LEMOS, 2018. 